\begin{tabular}{|c|l|}
\hline Title & $\begin{array}{l}\text { Plastic Responses to Different Types of Cue : Predator-Induced and Deep-W ater-Induced Poly phenisms in a } \\
\text { Salamander Hynobius retardatus }\end{array}$ \\
\hline Author(s) & Hangui, Jun-ichi; Wakahara, Masami; Michimae, Hirofumi \\
\hline Citation & $\begin{array}{l}\text { Zoological Science, 26(2), 119-124 } \\
\text { https://doi.org/10.2108/2s.26.119 }\end{array}$ \\
\hline Issue Date & 2009-02 \\
\hline Doc URL & http://hdl.handle.net/2115/42592 \\
\hline Type & article \\
\hline File Information & zs__26_119.pdf \\
\hline
\end{tabular}

Instructions for use 


\title{
Plastic Responses to Different Types of Cue: Predator-Induced and Deep-Water-Induced Polyphenisms in a Salamander Hynobius retardatus
}

\author{
Jun-ichi Hangui, Masami Wakahara and Hirofumi Michimae* \\ Division of Life System Sciences, Faculty of Advanced Life Science, \\ Hokkaido University, Sapporo 060-0810, Japan
}

\begin{abstract}
Certain plastic morphological responses of animals induced across a range of environmental conditions may be adapted for effective locomotor performance. Larvae of the salamander, Hynobius retardatus, occasionally swim upward to the surface to breathe air because aquatic respiration alone is insufficient to meet their increasing respiratory requirements for growth. We hypothesized that $\boldsymbol{H}$. retardatus larvae living in deep water would show an induced plastic response affecting locomotor structures, namely, a deeper tail, similar to that induced by predatory dragonfly larvae (Aeschna juncea), to improve their swimming performance. In this study, larval salamanders responded similarly to different cues (waterborne chemicals in a predatory environment and distance to the water's surface) by developing deeper tails. The similar modifications in tail shape presumably increase a larva's swimming performance, thereby improving its ability both to escape an attacking predator and to swim to the surface for air. The response in tail shape induced by the predatory environment was rapid, but was more gradual in larvae raised in deep water, suggesting that animals may quickly assess a dangerous environment and immediately respond, whereas assessment of an environment not requiring an immediate response for survival may be slower, accounting for the delayed response.
\end{abstract}

Key words: locomotor performance, phenotypic plasticity, surfacing, swimming, performance, predation

\section{INTRODUCTION}

Variation in the size or shape of the morphological structures of an organism may be functionally related to variation in the physical environment or the ecological community in which the organism lives (Futuyma, 1998). In particular, many morphological features of animals are thought to be adapted for effective locomotor performance (Alexander, 2006), and some of these features may be environmentdependent responses; that is, they may be examples of phenotypic plasticity (West-Eberhard, 2003). Thus, detection of phenotypically plastic morphological responses to the specific environmental conditions in which the animals live could provide critical insight into functional relationships between specific plastic morphologies and locomotor performance, and therefore into the behavior and ecology of the animals.

Many cases of phenotypic plasticity in locomotor structures have been documented in amphibian larvae (Van Buskirk and McCollum, 2000; Hoff and Wassersug, 2000; Wilson et al., 2005). Larval amphibians exhibit strong behavioral and morphological responses to the presence of predators, especially predatory dragonfly larvae, and the most

\footnotetext{
* Corresponding author. Phone: +81-3-5791-6322;

Fax : +81-3-3444-2546;

E-mail: michimaeh@pharm.kitasato-u.ac.jp

† Present address: School of Pharmacy, Department of Clinical Medicine (Biostatistics) Kitasato University, 5-9-1 Shirokane, Minato-ku, Tokyo 108-8641, Japan doi:10.2108/zsj.26.119
}

commonly reported predator-induced morphological change is an increase in relative tail depth (Van Buskirk and Schmidt, 2000; Relyea, 2002). Michimae and Hangui (2008) recently reported that larvae of the salamander Hynobius retardatus develop a deeper tail as an induced response to predatory dragonfly larvae (Aeschna juncea). The plastic response of the salamander larvae to the presence of a predation threat was qualitatively similar to that previously found in anuran tadpoles and salamander larvae in response to chemical cues from a predatory dragonfly (Van Buskirk and Schmidt, 2000; Relyea, 2002).

Whether amphibian larvae with relatively deeper tails display increased survival has been a source of some debate. First, it has been reported that a deeper tail enhances swimming performance, thus making escape from predator encounters more likely (Hale, 1996; Fitzpatrick et al., 2003; Wilson et al., 2005). Other studies, however, have reported that predator-induced variations in tadpole tail shape have very little effect on swimming performance (Hoff and Wassersug, 2000; Van Buskirk and McCollum, 2000). Instead, deeper and larger tails may attract predator strikes to the more expendable tail region and away from the more vulnerable head-body and core muscle regions (Doherty et al., 1998; Van Buskirk et al., 2003), because a ruptured body wall is almost certainly lethal, whereas sections of the tail can be torn away, allowing the tadpole to escape.

Variation in the physical environment can also affect morphological variation and thus result in variation in locomotor performance. For example, salamander larvae living 
in ponds have large dorsal fins that extend from the tip of the tail to the shoulder region, probably facilitating stability for swimming in the pond environment (Petranka, 1998). However, salamander larvae living in streams have smaller fins restricted to the tail, which is more suitable to a fastflowing water environment, where extra body surface area would be a distinct disadvantage (Petranka, 1998). These differences are thought to be adaptations to locomotion in still versus flowing water (Duellman and Trueb, 1986).

Although $H$. retardatus larvae spend most of their time at the bottom of a tank or pond (personal observation), they occasionally breathe air both under experimental conditions and in natural ponds. Even adult salamanders such as mudpuppies, which are paedomorphic and both utilize their skin and have efficacious external gills for gas exchange (Guimond and Hutchison, 1973), sometimes breathe air. It is not clear whether aquatic respiration alone is sufficient to meet a larva's increasing respiratory requirements with growth (Crowder et al., 1998), or if air breathing is required for growth, normal lung development, and successful metamorphosis (Proynch and Wassersug, 1994). In general, larval anurans show a variety of morphological and physiological responses to an increasing need for oxygen (Burggren and Infantino, 1994). However, air breathing also may be an essential behavioral response to an increasing need for oxygen. Air-breathing larvae of the salamander $H$. retardatus apparently rely upon atmospheric air as a supplemental source of oxygen, so they frequently need to swim upward to the water's surface to breathe. We hypothesize that $H$. retardatus larvae living in deep water should show a plastic response in a locomotor structure, such as a deeper tail, to enhance swimming performance. Such a plastic morphological trait would allow the salamander larvae to swim more rapidly from the bottom of a pond to the surface.

If such phenotypic plasticity in locomotor structures exists, then we also hypothesize that predator- and deepwater-induced plastic locomotor structures may be similar despite their being induced in salamander larvae by clearly different cues. In this study we investigated the hypothesis that, even though the plasticity is triggered by different types of cue (i.e., distance from the water surface and chemical signals from predators), plastic responses in predator- and deep-water-induced locomotor structures should be similar, because both environments require improved swimming performance. Because induction of new morphologies typically requires from days to weeks, there may be a time lag between the environmental change and the morphological response. Organisms that show long lag times in the development of functionally important plastic traits may be unable to accurately match their responses to environmental demands (Padilla and Adolph, 1996; DeWitt et al., 1998). Thus, in this study, we also estimated and compared the magnitude of the time delay in the expression of plastic locomotor structures by $H$. retardatus larvae between a predatory environment and a deep-water environment.

\section{MATERIALS AND METHODS}

\section{Egg collection}

In early May 2004, we collected fertilized egg clutches of the salamander $H$. retardatus from ponds at Atsuta (see Fig. 1 of Michimae, 2006) in the vicinity of Sapporo, Japan. Each collected
(A)

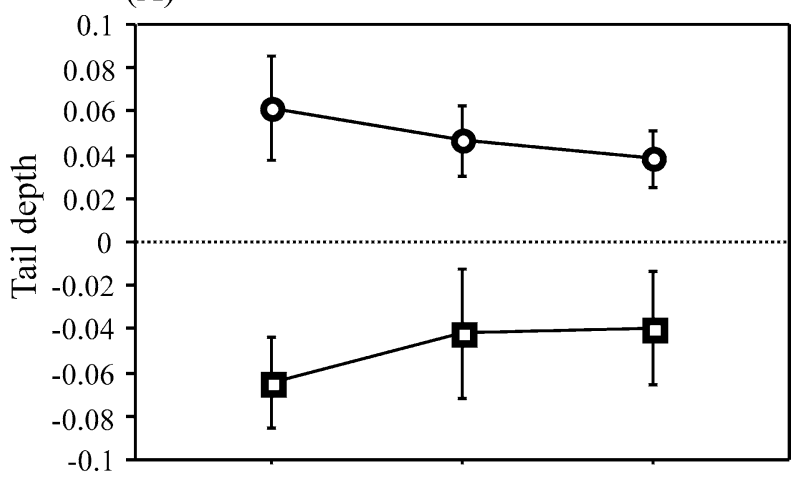

(B)

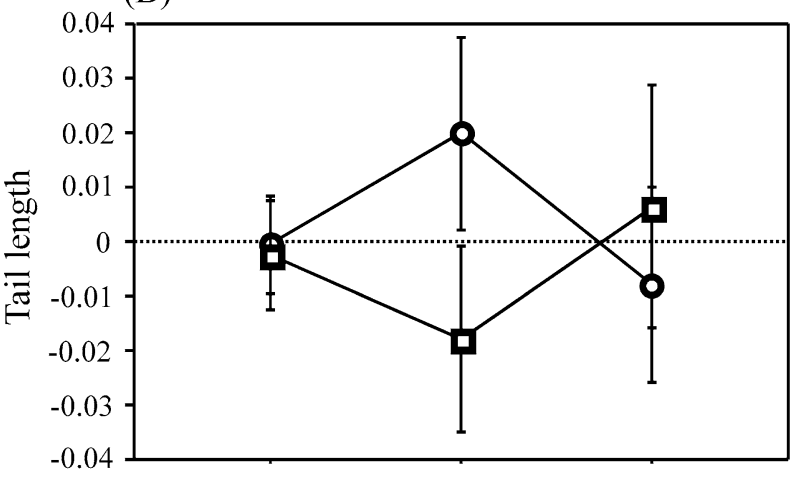

(C)

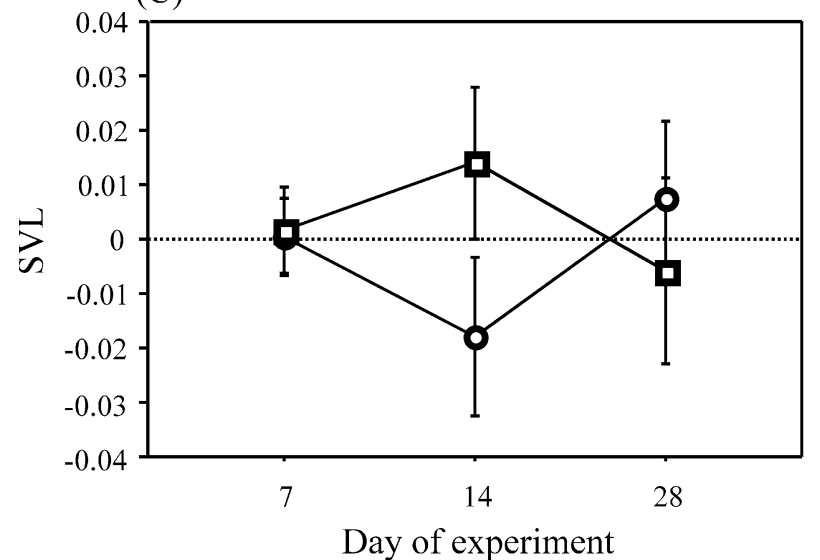

Fig. 1. In experiment 1 (predation risk: present or absent), predation risk increased tail depth (A) but did not alter tail length (B) or SVL (C) of larval Hynobius retardatus at 7 days, 14 days, or 28 days. Circles, predation risk; squares, no predation risk. Data are means \pm SD.

clutch was placed separately in a stock tank filled with $1.6 \mathrm{~L}$ of dechlorinated tap water at room temperature $\left(20-21^{\circ} \mathrm{C}\right)$ and left until hatching. After five clutches of salamanders had simultaneously hatched, all newly hatched larvae were collected into a single tank (30 cm long, $25 \mathrm{~cm}$ wide, $17.5 \mathrm{~cm}$ deep) filled with $5 \mathrm{~L}$ of dechlorinated tap water, and we then randomly selected 60 from the larger pool of larvae for each experiment (experiments 1 and 2). Both experiments were conducted at our laboratory in Hokkaido University.

\section{Experiment 1}

For experiment 1, we designed two distinct experimental con- 
ditions, with and without predation threat (larvae of the dragonfly Aeschna juncea). Sixty randomly chosen larvae were exposed to one of these two conditions. The 60 larvae were equally divided into six tanks (22 cm long, $15 \mathrm{~cm}$ wide, $12.5 \mathrm{~cm}$ deep), each with 10 larvae. Thirty larvae were raised in tanks containing $1.6 \mathrm{~L}$ of dechlorinated tap water, and the other 30 were raised in tanks containing $1.6 \mathrm{~L}$ of water in which dragonfly larvae had been reared. Ten salamander larvae, all from a single tank for each treatment, were removed, euthanized by immersion in $0.1 \%$ benzocaine, and then fixed in $4 \%$ paraformaldehyde at 7,14 , and 28 days after the beginning of the experiment. We measured overall body length (snout to tail tip), and three morphological variables, tail length, snout-vent length (SVL), and maximum tail depth in lateral view, to the nearest $0.05 \mathrm{~mm}$ with calipers. Actual values of overall body length, SVL, tail length and tail depth at 7, 14, and 28 days are listed in Table 1.

We substituted water in which dragonfly larvae had been reared for the presence of the predators themselves, because $H$. retardatus larvae are known to develop predator-induced morphology just in response to chemical cues from predators (Michimae and Hangui, 2008). The dechlorinated tap water or rearing water of dragonfly larvae was exchanged daily during the experiment. The dragonfly larvae rearing water was prepared by placing three dragonfly larvae in a tank (22 cm long, $15 \mathrm{~cm}$ wide, $12.5 \mathrm{~cm}$ deep) for 1 day before using the water from the tank in the experiment. The dragonfly larvae were fed salamander larvae, but they were not fed during the 1-day period when the rearing water was conditioned.

The salamander larvae used for this experiment were fed by offering frozen Chironomidae from 9:00 A.M. to 12:00 noon every other day. They were always given $3 \mathrm{~h}$ to eat the food, and any food remaining in their tanks was removed after the feeding period. All

Table 1. Actual values of overall body length $(\mathrm{mm}), \mathrm{SVL}(\mathrm{mm})$, tail length $(\mathrm{mm})$, and tail depth $(\mathrm{mm})$ of larval Hynobius retardatus in experiments 1 (predation risk: present or absent) and 2 (water depth: shallow or deep) at 7 days, 14 days, and 28 days. Data are means (1 SD).

\begin{tabular}{|c|c|c|c|}
\hline & \multicolumn{3}{|c|}{ Day after experiment } \\
\hline & 7 days & 14 days & 28 days \\
\hline \multicolumn{4}{|l|}{ Experiment 1 (predation risk) } \\
\hline \multicolumn{4}{|l|}{ Overall body length (mm) } \\
\hline no risk: mean (1 SD) & $31.45(0.26)$ & $34.91(5.32)$ & $42.65(7.63)$ \\
\hline risk: mean (1 SD) & $31.86(0.52)$ & $38.14(5.38)$ & $41.90(11.89)$ \\
\hline \multicolumn{4}{|l|}{ SVL (mm) } \\
\hline no risk: mean (1 SD) & $17.52(0.29)$ & $19.30(2.79)$ & $23.23(2.17)$ \\
\hline risk: mean (1 SD) & $17.76(0.39)$ & $20.60(3.66)$ & $23.20(5.91)$ \\
\hline \multicolumn{4}{|l|}{ Tail length (mm) } \\
\hline no risk: mean (1 SD) & $13.93(0.24)$ & $15.60(1.41)$ & $19.42(4.61)$ \\
\hline risk: mean (1 SD) & $14.10(0.21)$ & $17.60(1.25)$ & $18.70(2.30)$ \\
\hline \multicolumn{4}{|l|}{ Tail depth (mm) } \\
\hline no risk: mean (1 SD) & $5.34(0.18)$ & $5.88(0.32)$ & $7.77(0.58)$ \\
\hline risk: mean (1 SD) & $6.31(0.23)$ & $7.14(0.18)$ & $8.26(0.49)$ \\
\hline \multicolumn{4}{|l|}{ Experiment 2 (water depth) } \\
\hline \multicolumn{4}{|l|}{ Overall body length $(\mathrm{mm})$} \\
\hline shallow: mean (1 SD) & $31.53(0.34)$ & $35.91(2.56)$ & $39.85(1.75)$ \\
\hline deep: mean (1 SD) & $31.60(0.63)$ & $37.22(3.60)$ & $39.69(4.23)$ \\
\hline \multicolumn{4}{|l|}{ SVL (mm) } \\
\hline shallow: mean (1 SD) & $17.38(0.26)$ & $19.60(2.39)$ & $21.50(0.81)$ \\
\hline deep: mean (1 SD) & $17.26(0.28)$ & $19.80(1.56)$ & $20.62(1.64)$ \\
\hline \multicolumn{4}{|l|}{ Tail length (mm) } \\
\hline shallow: mean (1 SD) & $14.15(0.16)$ & $16.30(2.58)$ & $18.35(0.80)$ \\
\hline deep: mean (1 SD) & $14.34(0.57)$ & $17.40(0.87)$ & $19.07(2.11)$ \\
\hline \multicolumn{4}{|l|}{ Tail depth (mm) } \\
\hline shallow: mean (1 SD) & $5.52(0.05)$ & $5.97(0.22)$ & $8.52(0.20)$ \\
\hline deep: mean (1 SD) & $5.55(0.05)$ & $6.67(0.20)$ & $9.75(0.75)$ \\
\hline
\end{tabular}

experiments were conducted at room temperature $\left(20-21^{\circ} \mathrm{C}\right)$ in the laboratory under a natural light/dark schedule.

\section{Experiment 2}

For experiment 2, the other 60 larvae were assigned to one of two water depths, shallow water or deep water. The 60 larvae were divided equally into six experimental tanks $(34.5 \mathrm{~cm}$ long, $40.5 \mathrm{~cm}$ wide, $61 \mathrm{~cm}$ deep), each with 10 larvae. Thirty larvae were raised in experimental tanks containing $78 \mathrm{~L}$ of dechlorinated tap water (water depth, about $56 \mathrm{~cm}$ ), and the other 30 were raised in cages (33 $\mathrm{cm}$ long, $38 \mathrm{~cm}$ wide, $15 \mathrm{~cm}$ deep) with plastic mesh sides (mesh size, $3 \mathrm{~mm}$ ) and a plastic plate bottom (thickness, $3 \mathrm{~mm}$ ) that hung from the edge of experimental tanks containing $78 \mathrm{~L}$ of dechlorinated tap water. In each cage, the distance from the bottom of the cage to the water's surface (i.e., the water depth) was about $10 \mathrm{~cm}$. Ten salamander larvae all from a single tank in each treatment were removed, euthanized by immersion in $0.1 \%$ benzocaine, and fixed in $4 \%$ paraformaldehyde at 7,14 , and 28 days after the beginning of the experiment. We measured overall body length, and three morphological variables, tail length, SVL, and maximum tail depth in lateral view, to the nearest $0.05 \mathrm{~mm}$ with calipers. Actual values of overall body length, SVL, tail length and tail depth at 7 , 14 , and 28 days are listed in Table 1.

The larvae used for this experiment were fed by offering frozen Chironomidae from 9:00 A.M. to 12:00 noon every other day. Each group of 10 larvae in the cages and in the deep water was transferred from the experimental tank to another tank $(22 \mathrm{~cm}$ long, 15 $\mathrm{cm}$ wide, $12.5 \mathrm{~cm}$ deep), allowed $3 \mathrm{~h}$ to eat the food, and then transferred back to the experimental tank. The water in the tanks was exchanged every other day during the experiment. All experiments were conducted at room temperature in the laboratory under a natural light/dark schedule.

\section{Statistical analyses}

Apparent differences in morphology can be caused by differences in overall size as well as by differences in shape. Therefore, to examine relative differences in morphology, we regressed the three log-transformed linear measurements of morphological variables against the log-transformed body length of each individual in each experiment. We obtained regression lines for larvae at 7,14 , and 28 days in experiments 1 and 2 , and calculated the values of the residuals from these lines for each salamander larva. These size-independent measures then served as our primary response variables. The effects of water depth or predation threat, day of experiment, and interactions of the two factors on salamander larvae were analyzed by using multivariate analysis of variance (MANOVA). After MANOVA, we assessed which variables were responsible for significant main effects by univariate analysis of variance (one-way ANOVA) of each response variable.

\section{RESULTS}

\section{Experiment 1}

The MANOVA results showed a significant effect of predation threat, but insignificant effects of day of experiment and the interaction between day of experiment and predation threat (Table 2a; Fig. 1). The individual ANOVA results showed that of the three morphological variables (SVL, tail length, and tail depth) measured, only tail depth was significantly different between treatments (Table $2 \mathrm{~b}$ and Fig. 1). Salamander larvae with predation threat had deeper tails than the control salamander larvae without predation threat (Fig. 1). Differences in tail depth between the predationthreat and no-predation-threat treatments first appeared by 7 days, and were maintained over the next three weeks (Fig. 1). 
Table 2. Results of MANOVA for effects of day of experiment and predation threat on three morphological traits (SVL, tail length, and tail depth,). ANOVA results for each response variable are also shown.

\begin{tabular}{lrlllr}
\hline a) MANOVA & & & & \\
Factor & Wilks' lambda & d.f. & \multicolumn{1}{c}{$F$} & \multicolumn{1}{c}{$P$} \\
\hline Day of experiment & 0.9455 & 6,104 & 0.500 & 0.8074 \\
Predation threat & 0.635 & 3,52 & 9.947 & $<0.0001$ \\
Day of experiment * Predation threat & 0.815 & 6,104 & 1.869 & 0.093
\end{tabular}

b) ANOVAs

\begin{tabular}{lrrrr} 
Variables & \multicolumn{1}{c}{ MS } & d.f. & \multicolumn{1}{c}{$F$} & $P$ \\
\hline SVL & & & & \\
$\quad$ Day of experiment & $5.287 \mathrm{E}-5$ & 2,54 & 0.031 & 0.9691 \\
$\quad$ Predation threat & 0.001 & 1,54 & 0.391 & 0.5346 \\
$\quad$ Day of experiment * Predation threat & 0.003 & 2,54 & 1.584 & 0.2146 \\
Tail length & & & & \\
$\quad$ Day of experiment & $3.380 \mathrm{E}-5$ & 2,54 & 0.013 & 0.9875 \\
$\quad$ Predation threat & 0.001 & 1,54 & 0.404 & 0.5276 \\
$\quad$ Day of experiment * Predation threat & 0.004 & 2,54 & 1.322 & 0.2751 \\
Tail depth & & & & \\
$\quad$ Day of experiment & $7.416 \mathrm{E}-5$ & 2,54 & 0.015 & 0.9853 \\
$\quad$ Predation threat & 0.142 & 1,54 & 28.451 & $<0.0001$ \\
Day of experiment * Predation threat & 0.003 & 2,54 & 0.645 & 0.5286 \\
\hline
\end{tabular}

\section{Experiment 2}

Significant multivariate effects were associated with two factors (day of experiment and water depth) and with the interaction between the two factors (Table 3a). Subsequent ANOVA detected a significant effect of water depth on larval tail depth, and a significant interactive effect between day of experiment and water depth on larval tail depth (Table 3b; Fig. 2). Salamander larvae in deep water had deeper tails than control salamanders in shallow water (Fig. 2). Differences in tail depth between the shallow and deep-water treatments appeared gradually, as shown by the significant effect of the interaction between day of experiment and water depth on tail depth (Table 3b; Fig. 2).

Table 3. Results of MANOVA for effects of day of experiment and water depth on three morphological traits (SVL, tail length, and tail depth). ANOVA results for each response variable are also shown.

\begin{tabular}{lrrrr}
\hline a) MANOVA & Wilks' lambda & d.f. & \multicolumn{1}{c}{$F$} & \multicolumn{1}{c}{$P$} \\
$\quad$ Factor & 0.690 & 6,104 & 3.532 & 0.0032 \\
\hline Day of experiment & 0.596 & 3,52 & 11.754 & $<0.0001$ \\
Predation threat & & & & \\
Day of experiment * Predation threat & 0.668 & 6,104 & 3.877 & 0.0016 \\
& & & & \\
b) ANOVAs & MS & d.f. & $F$ & $P$ \\
$\quad$ Variables & & & & \\
\hline SVL & $7.167 \mathrm{E}-7$ & 2,54 & 0.048 & 0.9528 \\
$\quad$ Day of experiment & 0.003 & 1,54 & 1.871 & 0.1771 \\
$\quad$ Predation threat & $2.049 \mathrm{E}-4$ & 2,54 & 0.138 & 0.8712 \\
$\quad$ Day of experiment * Predation threat & & & & \\
Tail length & $7.093 \mathrm{E}-6$ & 2,54 & 0.004 & 0.9963 \\
$\quad$ Day of experiment & 0.004 & 1,54 & 2.317 & 0.1338 \\
$\quad$ Predation threat & $2.482 \mathrm{E}-2$ & 2,54 & 0.129 & 0.8790 \\
$\quad$ Day of experiment * Predation threat & & & & \\
$\quad$ Tail depth & $4.089 \mathrm{E}-5$ & 2,54 & 0.014 & 0.9859 \\
$\quad$ Day of experiment & 0.083 & 1,54 & 28.881 & $<0.0001$ \\
$\quad$ Predation threat & 0.023 & 2,54 & 7.941 & 0.0009 \\
$\quad$ Day of experiment * Predation threat & & & &
\end{tabular}
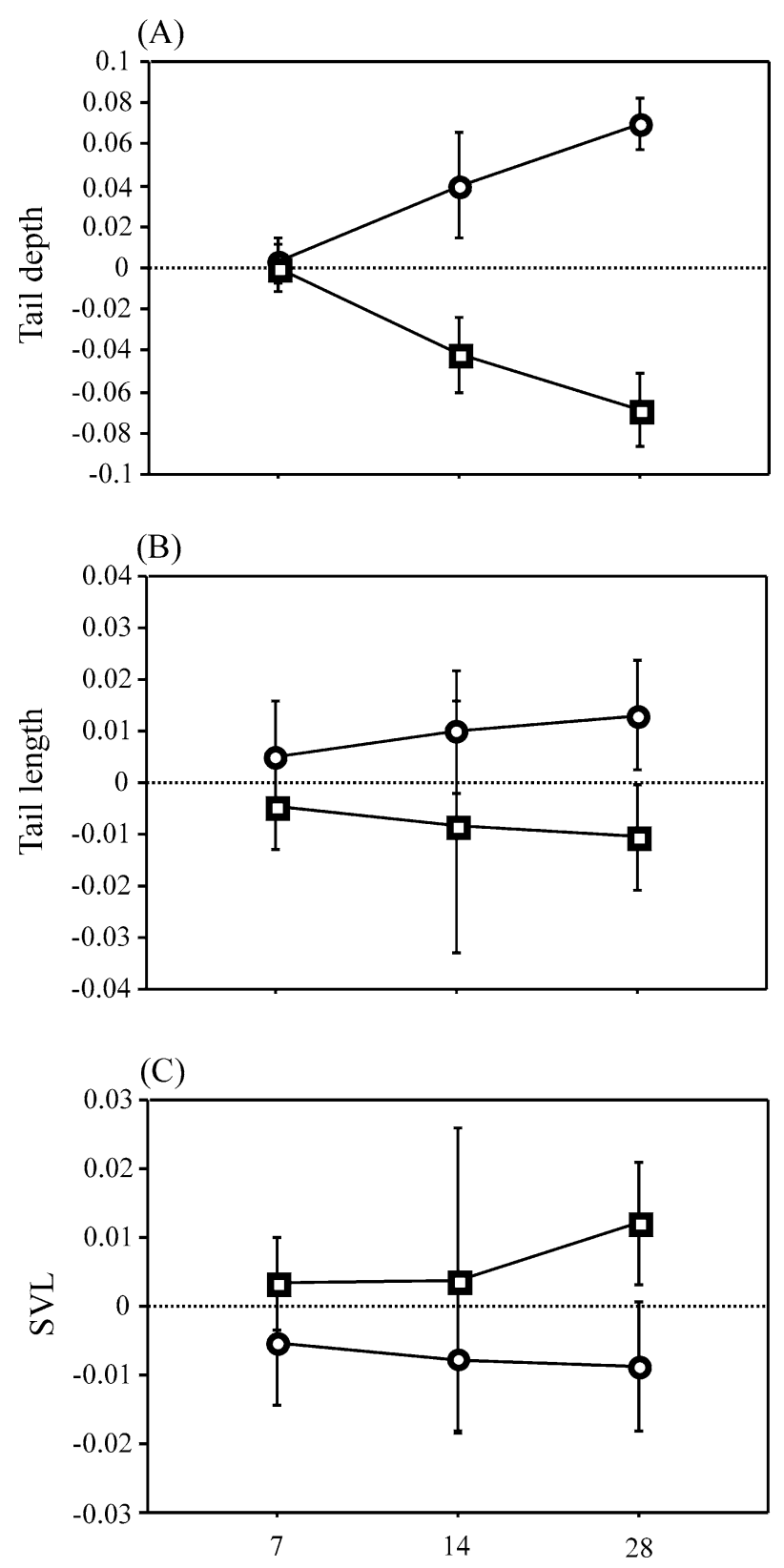

Day of experiment

Fig. 2. In experiment 2 (water depth: shallow or deep), greater water depth increased tail depth (A) but did not alter tail length (B) or SVL (C) of larval Hynobius retardatus at 7 days, 14 days, or 28 days. Circles, deep water; squares, shallow water. Data are means \pm SD.

\section{DISCUSSION}

\section{Predator-induced polyphenism}

Amphibian larvae have been the focus of several recent studies of predator-induced defenses, showing induced changes in behavior, shape, and color when exposed to predatory dragonfly larvae (Van Buskirk and Schmidt, 2000; Relyea, 2002). Deeper tails should allow an individual to displace more water when swimming and may increase initial 
burst speed and turn speed relative to larvae with shallower tails (Hale, 1996; Fitzpatrick et al., 2003; Wilson et al., 2005). Our present (Table 2; Fig. 1) and previous study (Michimae and Hangui, 2008) have presented the results of experiments that address morphological phenotypic responses of larvae of the salamander Hynobius retardatus to an invertebrate predator, the larval dragonfly Aeschna juncea. Our results are consistent with improvement of escape ability as the explanation for predator-induced tail polyphenism in amphibian larvae (Hale, 1996; Fitzpatrick et al., 2003; Wilson et al., 2005), although others studies suggest that predator-induced tail polyphenisms such as a deeper tail and thus enlarged fins may limit the predator's ability to grasp the fin and block the predator from planting its jaws into core muscle (Doherty et al., 1998) or the headbody region (Van Buskirk et al., 2003).

\section{Deep water-induced polyphenism}

Hynobius retardatus larvae require frequent access to the water's surface to gulp air. We tested whether the tail shape of this salamander responds plastically to water depth, and found that salamander larvae raised in deep water had deeper tails relative to control salamanders raised in shallow water (Table 3; Fig. 2). Our results imply a functional link between the shape of the tail and locomotor performance in $H$. retardatus larvae. In particular, the positive association between tail depth and water depth (Table 3; Fig. 2) is consistent with the proposition that the large tails of salamander larvae living in ponds are adaptations for rapid acceleration in still water (Duellman and Trueb, 1986). Therefore, in $H$. retardatus larvae, a relatively deeper tail may enhance swimming speed and acceleration, thereby improving a larva's ability to swim to the water's surface to gulp air. We can infer the advantages or benefits of the tail modifications in $H$. retardatus larvae from the findings of previous studies. First, Feder (1984) reported that salamander larvae rely on air breathing when dissolved oxygen is low; air breathing has an obvious advantage in hypoxic waters, because denying surface access to larval salamanders under hypoxic conditions usually kills them. Crowder et al. (1998) also reported that surfacing to breathe may be advantageous to a large larva when aquatic respiration alone is insufficient to meet its respiratory requirements. Second, Feder (1984) suggested that air breathing may simply be a matter of precocial development of the lungs, which will become the major gas exchange organ in the adult, and one advantage of precocious air breathing may be to facilitate metamorphosis.

\section{Comparison between predator- and deep-water-induced polyphenisms}

Considering the plastic response to predatory threat (Fig. 1) along with the plastic response to water depth (Fig. 2 ), which are induced by different types of cues in entirely different circumstances, may help us identify a functional relationship between the plastic trait (tail depth) and locomotor performance. These similar inducible modifications in larval tail shape should lead to improved larval swimming performance, as described above (Hale, 1996; Fitzpatrick et al., 2003; Wilson et al., 2005), thereby improving the larva's ability to escape an attacking predator and its ability to swim to the water's surface to gulp air, because salamander larvae in deep (and predator free) water have no need to acquire deep tails to entice predatory dragonflies to grasp the attractive tails.

The morphological response to the deep-water environment may therefore appear later than the morphological response to the predatory environment (Figs. 1,2). Plasticity can be limited when developmental shifts in phenotypes involve time delays (Padilla and Adolph, 1996; DeWitt et al., 1998). A lag time is not interpreted as a reflection of developmental capabilities, because the plastic responses in the two experimental conditions are thought to be based on the same developmental system. Alternatively, the lag time may be caused by slow assessment of water depth. Although we did not attempt to identify the environmental cue(s) that may signal water depth in this experimental system, the environmental cue(s) are likely related to the swimming volume and perhaps the distance to the water's surface (Denver et al., 1998). Animals may quickly assess a dangerous environment such as a predation risk and may immediately respond to that environment, because a delayed plastic response to environmental variability would be maladaptive if delayed expression increases the likelihood of a mismatch between the phenotype and the environment (Moran, 1992). However, assessment of an environment in which the animal need not respond immediately for survival may be slower, and therefore the response may be delayed.

\section{ACKNOWLEDGMENTS}

This work was supported by a Grant-in-Aid for Scientific Research (No. 15009850) from the Japan Society for the Promotion of Science.

\section{REFERENCES}

Alexander RM (2006) Principles of Animal Locomotion. Princeton University Press, Princeton

Burggren WW, Infantino RL Jr (1994) The respiratory transition from water to air breathing during amphibian metamorphosis. Am Zool 34: 238-246

Crowder WC, Nie CM, Ultsch GR (1998) Oxygen uptake in bullfrog tadpoles (Rana catesbeiana). J Exp Zool 280: 121-134

Denver RJ, Mirhadi N, Phillips M (1998) Adaptive plasticity in amphibian metamorphosis: response of Scaphiopus hammondii tadpoles to habitat desiccation. Ecology 79: 1859-1872

DeWitt TJ, Sih A, Wilson DS (1998) Costs and limits of phenotypic plasticity. Trends Ecol Evol 13: 77-81

Doherty PA, Wassersug RJ, Lee JM (1998) Mechanical properties of the tadpole tail fin. J Exp Biol 201: 2691-2699

Duellman W E, Trueb L (1986) Biology of Amphibians. McGraw-Hill, New York

Feder ME (1984) Consequences of aerial respiration for amphibian larvae. In "Respiration and Metabolism of Embryonic Vertebrates" Ed by RS Seymour, Junk, Dordrecht, pp 71-95

Fitzpatrick BM, Benard MF, Fordyce JA (2003) Morphology and escape performance of tiger salamander larvae (Ambystoma tigrinum mavortium). J Exp Zool 297A: 147-159

Futuyma DJ (1998) Evolutionary Biology. 3rd ed, Sinauer, Sunderland

Guimond RW, Hutchison VH (1973) Pulmonary, branchial and cutaneous gas exchange in the mud puppy, Necturus maculosus maculosus (Rafinesque). Comp Biochem Physiol 42A: 367393

Hale ME (1996) The development of fast-start performance in fishes: escape kinetics of the Chinook Salmon (Onchorhynchus 
tshawytscha). Am Zool 36: 695-709

Hoff K. vS, Wassersug RJ (2000) Tadpole locomotion: axial movement and tail functions in a largely vertebraeless vertebrate. Am Zool 40: 62-76

Michimae H (2006) Differentiated phenotypic plasticity in larvae of the cannibalistic salamander Hynobius retardatus. Behav Ecol Sociobiol 60: 205-211

Michimae H, Hangui J (2008) A trade-off between prey- and predator-induced polyphenisms in larvae of the salamander Hynobius retardatus. Behav Ecol Sociobiol 62: 699-704

Moran NA (1992) The evolutionary maintenance of alternative phenotypes. Am Nat 139: 971-989

Padilla DK, Adolph SD (1996) Plastic inducible morphologies are not always adaptive: the importance of time delays in a stochastic environment. Evol Ecol 10: 105-117

Petranka JW (1998) Salamanders of the United States and Canada. Smithsonian Institution Press, Washington, DC

Proynch S, Wassersug RJ (1994) Lung use and development in Xenopus laevis tadpoles. Can J Zool 72: 738-743
Relyea RA (2002) Competitor-induced plasticity in tadpoles: consequences, cues, and connections to predator-induced plasticity. Ecol Monogr 72: 523-540

Van Buskirk J, McCollum SA (2000) Influence of tail shape on tadpole swimming performance. J Exp Biol 203: 2149-2158

Van Buskirk J, Schmidt BJ (2000) Predator-induced phenotypic plasticity in larval newts: trade-offs, selection, and variation in nature. Ecology 81: 3009-3028

Van Buskirk J, Anderwald P, Lupold S, Reinhard L, Schuler H (2003) The lure effect, tadpole tail shape, and the target of dragonfly strikes. J Herpetol 37: 420-424

West-Eberhard MJ (2003) Developmental Plasticity and Evolution. Oxford University Press, Oxford

Wilson RS, Kraft PG., Van Damme R (2005) Predator-specific changes in the morphology and swimming performance of larval Rana lessonae. Funct Ecol 19: 238-244

(Received September 4, 2008 / Accepted November 6, 2008) 